\title{
El perfil del usuario de información
}

\author{
Patricia Hernández Salazar ${ }^{\star}$
}

\section{RESUMEN}

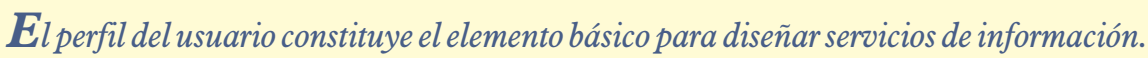
Para precisar perfiles de usuarios se debe seguir un proceso denominado Estudio de Usuarios. En el presente documento se enfatiza la importancia de los perfiles de usuarios como fundamento para planear cualquier servicio, unidad o sistema de información. Se conceptúa el uso de la información, asimismo, se definen las necesidades de información.

En la siguiente sección se precisan los antecedentes y el significado del perfil de usuarios, relacionándolo con los Estudios de Usuarios.

Finalmente, se describen a grandes rasgos las técnicas de investigación para determinar perfiles de usuarios, con el fin de que puedan ser utilizadas por la comunidad bibliotecaria interesada en este tema.

\section{ABSTRACT}

The user's profile is the key element to design information services.

In order to outline user's profiles, the so called Users Survey process must be carried out.

In this paper, the importance of user's profiles is emphasized as the starting point for the planning of any information service, unit, or system.

The concept of information usage is introduced, and the information needs are defined. In the next section, the background and meaning of the user's profile are dealt with by relating it to the Survey of Users.

Finally, research techniques to determine user's profile are described in general terms, so that they can be used by the library community interested in this topic.

\section{INTRODUCCIÓN}

La razón de ser de cualquier entidad dedicada a ofrecer servicios de información es el usuario.

El usuario es el personaje principal de la trama informática, es el principio y fin del ciclo de transferencia de la información: él solicita, analiza, evalúa y recrea la información.

Por tanto, la creación, organización y evaluación de unidades de informa- ción están determinadas por las necesidades de sus usuarios, ya sean estos reales o potenciales.

Si bien lo anterior es evidente, por lo mismo pasa desapercibido y no se toma en cuenta al planear servicios de información.

Precisar las características de la comunidad de usuarios, incluyendo sus necesidades de información, debe ser una actividad sistematizada y fundamentada en conceptuaciones bibliotecológicas generales, con el fin de imprimirle un carácter científico.

\section{USO DE LA INFORMACIÓN}

Como primer paso para determinar las necesidades de información de comunidades de usuarios se debe conceptuar el fenómeno uso de la información.

* Investigadora del Centro Universitario de Investigaciones Bibliotecológicas 
Después de la Segunda Guerra Mundial, el término "información" adquirió gran popularidad; para cada comunidad disciplinaria ha tenido una connotación diferente: en el área bibliotecológica se puede definir a la "información" como un conjunto de datos transmitidos a través de la comunicación. ${ }^{1}$ Dichos datos son interpretados por el receptor y se espera una respuesta al estímulo informativo.

Pero para que esta interpretación se dé, el receptor debe poseer una infraestructura cognoscitiva determinada sobre cierta área del conocimiento o del saber empírico.

Ahora bien, "el conocimiento es todo lo que un ser ha aprendido o asimilado -valores, así como hechos o información-, y organizado de acuerdo a aquellos conceptos, imágenes o relaciones que ha podido dominar. ${ }^{2}$

De lo anterior se desprenden varias conclusiones: la información representa una de las formas comunicables de la estructura del conocimiento a través de datos; existe una diferencia esencial entre los términos "información" y "conocimiento"; y por último, información y conocimiento están íntimamente relacionados.

El saber empírico se refiere al conocimiento producido por la experiencia al manipular ciertos fenómenos cotidianos.

Asimismo, la motivación para buscar, recuperar y usar la información tiene un carácter eminentemente utilitario y de producción, Aun los investigadores que aparentemente utilizan información sin fines prácticos inmediatos, dicha utilización está fundamentada en la necesidad de producir conocimiento.

A través de la identificación de este acervo cognoscitivo del usuario, se podrán delimitar tipos de usuarios y, por consiguiente, sus perfiles de necesidades de información.

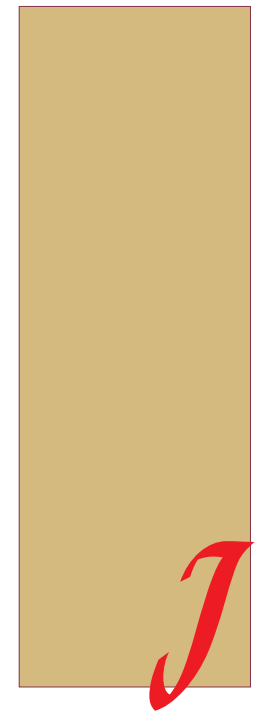

\section{NECESIDADES DE INFORMACIÓN}

Las necesidades de información de un individuo son aquellos conjuntos de datos que éste necesita poseer para cubrir un objetivo determinado.

Es importante distinguir entre las necesidades latentes y las necesidades expresadas (demandas) del usuario.

Una demanda es lo que el individuo realmente solicita al servicio de información sea utilizada en la recreación del conocimiento en una disciplina, o para ser aplicada en forma directa y aumentar el saber empírico.

Además de la estructura cognoscitiva del usuario, las necesidades de información están influidas por otros factores:

- Nivel de experiencia sobre la disciplina de interés.

- Tiempo de experiencia en la disciplina.

- Si el usuario trabaja en forma individual o grupal.

- Persistencia.

- Motivación.

- Capacidad de análisis de la información.

- Conciencia del universo de los recursos de información.

- Medio ambiente en el que se desarrolla el usuario: situación social, política y económica de su entorno.

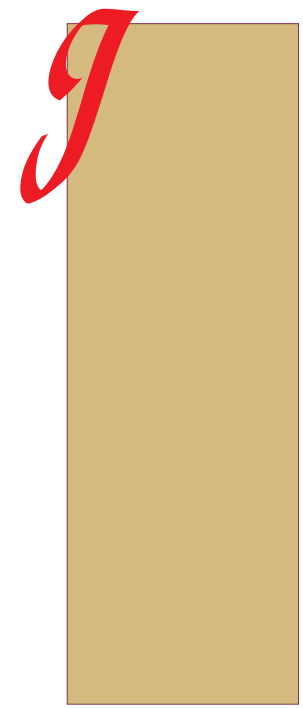

- Manejo del lenguaje. ${ }^{3}$

Las necesidades de información, así como otras características de comportamiento en el uso de la información, están contenidas en los perfiles del usuario. 


\section{PERFIL DEL USUARIO}

La presentación de las características del usuario debe ser sistematizada y consistente, a través de la precisión de su perfil.

El término perfil se deriva de la psicología, dentro de esta disciplina es entendido como el “....conjunto de medidas diferentes de una persona o grupo, cada una de las cuales se expresa en la misma unidad de medición...". ${ }^{4}$

Esto es, que ciertas características de un individuo son medidas mediante pruebas que arrojan puntuaciones diferentes, estas puntuaciones constituyen su perfil, el cual es utilizado con fines diagnósticos.

Dentro del área bibliotecológica, el vocablo perfil aparece relacionado con el servicio de Diseminación Selectiva de Información (DSI).

El DSI aparece a fines de la década de los cincuenta; fue concebido por H.P. Luhn como un servicio de información basado en el uso de la computadora, mediante el cual se haría llegar la producción novedosa de cualquier tipo de fuentes de información, a aquellas personas que de acuerdo a su trabajo o intereses les fuera útil. ${ }^{5}$

Para llevar a cabo el servicio de DSI se debía determinar un perfil, el cual representaba los intereses o necesidades de información de un usuario, establecidos de manera que facilitaban la identificación de los registros documentales que se relacionaran con esas necesidades dentro del sistema de información suministrador de los registros.

De tal manera, que el perfil se refería sólo a intereses o necesidades de información, se incluían datos generales para identificar a la persona y poder enviarle la información recuperada.

El perfil de intereses dentro de la computadora representaba la "forma física" de las necesidades de información del usuario, al indizar los documentos que ingresaban al sistema los términos que representaban a los documentos que fueran iguales a las necesidades ocupaban la "forma" del perfil del usuario.

Posteriormente, y debido a la creciente producción de recursos de información, se han ido ampliando las características que se incluyen en los perfiles; actualmente se especifican datos como: tipo de documento, autor, serie, fecha de publicación, etcétera, que hacen cada vez más especializados los perfiles.

Dada la aplicabilidad del concepto perfil, se ha sacado de su entorno original (DSI) y se ha ampliado para crear el concepto de perfil del usuario.

Por extensión, el perfil del usuario puede ser definido como el conjunto de rasgos distintivos que caracterizan al usuario.

Así como en el área psicológica los perfiles sirven para establecer el diagnóstico de una persona, en el área bibliotecología sirven para describir a un usuario, y en ambas disciplinas son utilizados como base para planear cualquier procedimiento a seguir.

Los datos que conforman un perfil de usuarios son:

- Disciplina de interés (necesidades de información).

- Nivel de escolaridad.

- Función o actividad principal: administrador, científico, investigador, alumno, etcétera.

- Recursos de información utilizados o requeridos: fuentes primarias o secundarias.

- Métodos para localizar la información: citas, uso de la biblioteca, colegio invisible, documentación personal, etcétera.
- Comportamiento en la búsqueda de información: búsqueda personal o delegada.

- Manejo del lenguaje.

La mayoría de perfiles de usuarios están basados en los supuestos de necesidades de información que los bibliotecarios creen detectar en los usuarios, sin probar o desaprobar dichos supuestos.

Para comprobar o no las inferencias de perfiles de usuarios se deben llevar a cabo Estudios de Usuarios, estos estudios nos arrojarán el perfil de los usuarios o comunidades seleccionadas.

\section{ESTUDIOS DE USUARIOS}

Los estudios de usuarios son un conjunto de técnicas de investigación social que sirven para determinar el comportamiento de los usuarios de información.

El objetivo práctico general de un estudio de usuarios es suministrar las bases para crear, planear o transformar un servicio, unidad o sistema de información. ${ }^{6}$

Asimismo, "están encaminados a comprender, justificar, explicar o extender la utilización de la biblioteca y, consecuentemente, obtener un mayor conocimiento sobre el proceso de la comunicación en lo que respecta a las bibliotecas y sus usuarios". ${ }^{7}$

Los objetivos específicos de los estudios de usuarios dependerán de las características a analizar, y pueden ser:

1. Detectar las necesidades de información del usuario. Mediante este estudio, se definen la forma (publicación periódica, enciclopedia, monografía, etcétera) y el contenido (tema) de la información requerida, lo que nos permite definir productos y servicios.

2. Detectar las necesidades de formación. Se analiza el comportamiento del usuario durante la búsqueda y recuperación de información, nos presenta cómo se satisfacen las necesidades de 
información lo que nos posibilita detectar la formación en el uso de recursos de información o la carencia de ésta.

3. Evaluar la satisfacción de usuarios. Se mide la pertinencia y relevancia de la recuperación de información, así como el tiempo de respuesta, accesibilidad y cobertura de los servicios de información. ${ }^{8}$

4. Detectar la actitud hacia la unidad o servicio de información. Se precisan los valores e imagen que los usuarios tiene de la información, las actividades y especialistas relacionados con esta, para así fundamentar los comportamientos y necesidades de los usuarios. ${ }^{9}$

Para realizar estudios de usuarios es requisito indispensable contar con diferentes tipos de información: bibliográfica (libros, artículo, informes, planes y programas de estudios, reglamentos, manuales de procedimientos, etcétera), estadística (datos sobre el uso de recursos de información, registro de usuarios, sugerencias de adquisición, etcétera), así como información sociológica (datos socioeconómicas) y psicológica (motivaciones y actitudes del usuario).

Para obtener perfiles de usuarios, los estudios que se deben realizar son los que están relacionados con el primer objetivo específico: detectar necesidades de información.

\section{TÉCNICAS PARA REALIZAR ESTUDIOS DE USUARIOS}

Las técnicas para recabar datos corresponden a las técnicas de investigación social y bibliotecológica:

- Bibliográfica

- Encuesta

Bibliográfica. Comprende el análisis e interpretación de los registros que se consideren relevantes sobre el tema, así como los documentos producto del servicio bibliotecario.
Encuesta. Técnica de campo, cuyo objetivo es obtener información que permita describir diversas facetas o situaciones de la comunidad bibliotecaria a estudiar. ${ }^{10}$

Los instrumentos para recabar datos en una investigación por encuesta pueden ser de tres tipos: cuestionarios, entrevistas y observación directa. Es posible y más aún recomendable la utilización de más de un tipo de instrumento.

Para llevar a cabo encuestas se requiere planearlas de forma sistematizada, de tal manera que los resultados sean confiables.

Los pasos principales para diseñar encuestas son los siguientes:

\section{Precisar los objetivos.}

2. Determinar la población de estudio.

3. Determinar el instrumento de recolección de datos y la forma de aplicación.

4. Diseñar el instrumento de recolección de los datos.

5. Pilotearlo.

6. Realizar ajustes (en caso que existan).

7. Seleccionar la muestra.

8. Aplicar el instrumento de recolección a la muestra seleccionada.

9. Tabular y presentar los resultados.

10. Analizar e interpretar los resultados,

11. Elaborar el informe final.

Cabe señalar que se debe elegir una característica a estudiar para cada encuesta, de tal manera que los resultados sean consistentes: si se pretende detectar necesidades de información para determinar perfiles de usuarios, no incluir reactivos sobre el grado de formación en el uso de información.

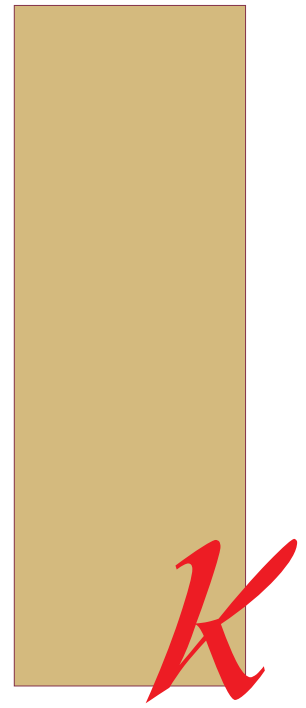

En el área bibliotecología los perfiles sirven para describir a un usuario, y en ambas disciplinas son utilizados como base para planear cualquier procedimiento a seguir.

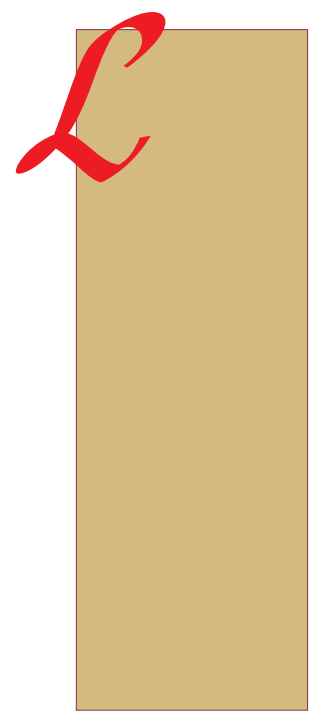


El diseño de instrumentos de medida es más sencillo si está dirigido a captar información sobre una determinada situación.

\section{APLICACIÓN DE TÉCNICAS DE ESTUDIOS DE USUARIOS PARA OBTENER PERFILES}

La elección de una técnica específica estará determinada por el uso que se haga de la información, el tipo de biblioteca y la cantidad de usuarios que concurran al servicio de información.

Se debe tener cuidado al determinar las necesidades de información, en general el bibliotecario se basa sólo en las demandas expresadas. Para evitar en lo posible este sesgo, es necesario combinar varias técnicas para que los datos sean útiles y confiables.

Por ejemplo, para determinar el perfil de los investigadores usuarios de bibliotecas especializadas de centro o institutos, se puede hacer uso de la técnica bibliográfica en primer término.

A través del análisis de diferentes tipos de documentos, se podrán determinar ciertas características.

Documentos internos del centro o instituto (catálogo de puestos, informes, reglamento interno, resúmenes de investigaciones, etcétera):

- Tema de investigación

- Título de la investigación

- Objetivos: general y específicos

- Metodología

- Bibliografía de apoyo
- Nivel académico del investigador

Publicaciones del centro o instituto:

- Cantidad de trabajos publicados en publicaciones periódicas nacionales.

- Cantidad de artículos publicados en publicaciones extranjeras. ${ }^{11}$

Trabajos publicados por los investigadores:

- Títulos más consultados.

- Antigüedad de la literatura citada.

- Porcentaje de las publicaciones citadas, que debieron buscarse fuera de la biblioteca.

- Autores más citados. ${ }^{12}$

Estadísticas de uso de la biblioteca:

- Temas más consultados de acuerdo al sistema de clasificación de la biblioteca.

- Títulos más consultados.

- Tipo de recursos de información.

Con esta primera técnica obtendremos un perfil derivado del análisis de documentos. Para reforzar o constatar dicho perfil, se puede levantar una encuesta entre los investigadores, a través de una entrevista u observación directa, con lo que captaremos los siguientes datos:

- Métodos para localizar la información
- Comportamiento en la búsqueda de información: búsqueda personal o delegada.

Asimismo, se verifican los datos obtenidos a través de la técnica bibliográfica.

\section{CONCLUSIONES}

El usuario debe ser el agente principal para planear y/o desarrollar servicios de información.

La infraestructura del conocimiento que un usuario tenga sobre una determinada disciplina, así como su saber empírico, determinarán las necesidades y uso que haga de la información.

Las necesidades de información, así como otras características del usuario, deben ser conocidas por el bibliotecario a través de la delimitación de perfiles.

Los perfiles derivarán de estudios de usuarios. Para realizar estudios de usuarios, existen dos técnicas de investigación, principalmente: la bibliográfica y la encuesta.

La encuesta está basada en la recopilación, análisis e interpretación de datos recolectados a través de tres instrumentos: cuestionario, entrevista y observación directa.

Dentro del informe final de los estudios de usuarios se precisa el perfil del usuario o comunidad de usuarios estudiada.

\section{OBRAS CONSULTADAS}

ASCENCIO ALMADA, Rafael Eduardo; GIL ORTEGA, Carlos Alberto. La transferencia electrónica de información a través de las fronteras y su impacto en las relaciones internacionales contemporáneas. México: El autor, $1989.158 \mathrm{p}$.

AÑORVE GUILLÉN, Martha. "La fiabilidad en la entrevista: la entrevista semiestructurada, un recurso de la encuesta". Investigación bibliotecológica: archivonomía, bibliotecología e información. 5 (10): 29-37, enero-junio, 1991. 
BUSHA, Charles H. Métodos de investigación en Bibliotecología: técnicas e interpretación. México, UNAM, Centro Universitario de Investigaciones Bibliotecológicas, 1990. 408 p.

DI VIETRO, María Teresa. "Los estudios de usuarios y su relación con la planificación bibliotecaria”. En: Bibliotecología y documentación. (6/11): pp. 15-23. Jul/dic. 1981. Ene-Jun, 1984.

DOYLE, Lauren B. Information retrieval and processing. Los Ángeles, Cal.: Melville Publishing Company, c1975. 410 p.

FORD, Geoffrey. Unisist guidelines for the conduct of user studies. Paris: Unesco, 1978. 158 p.

GOLDHOR, Herbert. Introducción a la investigación científica en bibliotecología, México: UNAM, c1981. 177p.

GORTARI, Elí de. Introducción a la lógica dialéctica. México: Fondo de Cultura Económica, UNAM, Instituto de Investigaciones Filosóficas. $338 \mathrm{p}$.

GUINCHAT, Claire y Michel Menou. Introducción general a las cienciasy técnicas de la información y la documentación. Uruguay: UNESCO, 1983. $480 \mathrm{p}$.

HOLGUÍN QUIÑONES, Fernando. Estadística descriptiva aplicada a las ciencias sociales. México: UNAM, Facultad de Ciencias Políticas y Sociales, 1984. $452 \mathrm{p}$.

KEMP, David Alasdair, Current awareness services. London: Clive Bingley, 1979. $181 \mathrm{p}$.

KERLINGER, Fred N. Investigación del comportamiento. México: Nueva Editorial Interamericana, 1982. 525 p.

MIKHAILOV, A. I. Scientific communications and informatics. Arlington, Virginia: Information Resources, 1984. 402 p.

LANCASTER, Frederick Wilfrid. Evaluación y medición de los servicios bibliotecarios. México: UNAM, Dirección General de Bibliotecas, 1983. 447 p.

-Information retrieval systems: caracteristics, testing and evaluation, New York: John Wiley \& Sons, c1968. 381 p.

-Practical current awareness services from libraries. Great Britain: Gower c1986. 109 p.

ROSZAK, Theodore. El culto a la información: el Folclore de los ordenadores y el verdadero arte de pensar. México; Grijalbo, 1990. 277 p.

ROWLEY, J. E. y C.M. D. Turnes. The dissemination of information, London: Andre Deutsch, 1978. 356 p.

SHERA, Jesse H. Los fundamentos de la educación bibliotecológica. México: UNAM, Centro Universitario de Investigaciones Bibliotecológicas, 1990. 520 p. 
STIBIC, Vladimir. Personal documentation for professionals. Amsterdam: North- Holland Pusblishing Company, 1983. 216 p.

\section{REFERENCIAS BIBLIOGRÁFICAS}

1. SHERA, Jesse H. Los fundamentos de la educación bibliotecológica. 1990. p. 167.

2. SHERA, Jesse H. Op. Cit.

3. ROWLEY, J. E. y C.M. D. Turnes. The dissemination of information, 1978. p. 54.

4. KERLINGER, Fred N.Investigación del comportamiento. 1982. p. 105.

5. MIKHAILOV, A. I. Scientific communications and informatics. Arlington, Virginia: Information Resources, 1984. p. 234.

6. GUINCHAT, Claire y Michel Menou. Introducción general a las ciencias y técnicas de la información y la documentación. 1983. p. 413.

7. BUSHA, Charles H. Métodos de investigación en Bibliotecología: técnicas e interpretación. 1990. p.161.

8. LANCASTER, Frederick Wilfrid. Evaluación y medición de los servicios bibliotecarios. 1983. p. 8-9.

9. GUINCHAT, Claire. Op. cit. p. 413.

10. BUSHA, Charles H. Op. cit. p. 55-56

11. DI VIETRO, María Teresa. "Los estudios de usuarios y su relación con la planificación bibliotecaria". En: Bibliotecología y documentación. (6/11): pp. 15-23. Jul/dic. 1981. Ene-Jun, 1984.

12. DI VIETRO, María Teresa. Op. cit. p.19 